OPEN ACCESS

Edited by:

Wim Van Hul,

University of Antwerp, Belgium

Reviewed by:

Cristina Sobacchi,

National Research Council (CNR), Italy

Alberto Falchetti,

Istituto Auxologico Italiano (IRCCS),

Italy

*Correspondence:

Emma L. Duncan

emma.duncan@kcl.ac.uk

Specialty section:

This article was submitted to

Bone Research,

a section of the journal

Frontiers in Endocrinology

Received: 13 November 2020

Accepted: 21 December 2020

Published: 19 February 2021

Citation:

Mclnerney-Leo AM and Duncan EL (2021) Massively Parallel Sequencing for Rare Genetic Disorders: Potential and Pitfalls.

Front. Endocrinol. 11:628946. doi: 10.3389/fendo.2020.628946

\section{Massively Parallel Sequencing for Rare Genetic Disorders: Potential and Pitfalls}

\author{
Aideen M. Mclnerney-Leo ${ }^{1}$ and Emma L. Duncan ${ }^{2 *}$ \\ ${ }_{1}^{1}$ Dermatology Research Centre, University of Queensland Diamantina Institute, The University of Queensland, Brisbane, \\ QLD, Australia, ${ }^{2}$ Department of Twin Research \& Genetic Epidemiology, Faculty of Life Sciences and Medicine, School of \\ Life Course Sciences, King's College London, London, United Kingdom
}

There have been two major eras in the history of gene discovery. The first was the era of linkage analysis, with approximately 1,300 disease-related genes identified by positional cloning by the turn of the millennium. The second era has been powered by two major breakthroughs: the publication of the human genome and the development of massively parallel sequencing (MPS). MPS has greatly accelerated disease gene identification, such that disease genes that would have taken years to map previously can now be determined in a matter of weeks. Additionally, the number of affected families needed to map a causative gene and the size of such families have fallen: de novo mutations, previously intractable by linkage analysis, can be identified through sequencing of the parent-child trio, and genes for recessive disease can be identified through MPS even of a single affected individual. MPS technologies include whole exome sequencing (WES), whole genome sequencing (WGS), and panel sequencing, each with their strengths. While WES has been responsible for most gene discoveries through MPS, WGS is superior in detecting copy number variants, chromosomal rearrangements, and repeat-rich regions. Panels are commonly used for diagnostic purposes as they are extremely cost-effective and generate manageable quantities of data, with no risk of unexpected findings. However, in instances of diagnostic uncertainty, it can be challenging to choose the right panel, and in these circumstances WES has a higher diagnostic yield. MPS has ethical, social, and legal implications, many of which are common to genetic testing generally but amplified due to the magnitude of data (e.g., relationship misattribution, identification of variants of uncertain significance, and genetic discrimination); others are unique to WES and WGS technologies (e.g., incidental or secondary findings). Nonetheless, MPS is rapidly translating into clinical practice as an extremely useful part of the clinical armamentarium.

Keywords: gene discovery, massively parallel sequencing, skeletal dysplasias, whole exome sequencing, rare genetic bone disorder 


\section{THE RECOGNITION OF RARE GENETIC DISORDERS}

In starting this paper exploring massively parallel sequencing (MPS) technologies for rare genetic disorders with particular reference to skeletal diseases, it is extremely fitting that the first description of any monogenic disorder was black bone disease (now known as alkaptonuria). Archibald Garrod, a UK physician, commented in 1902 that the constellation of symptoms constituting alkaptonuria "was apt to make its appearance in two or more brothers and sisters" (1). Increased occurrence in siblings does not necessarily indicate a genetic disorder (increased familiality may also reflect environmental sharing); but crucially Garrod also noted that they were commonly "the offspring of marriages of first cousins who did not themselves exhibit this anomaly ... and among whose forefathers there is no record of its having occurred". Through the world-wide dissemination of Gregor Mendel's gardening experiences (2), the modern reader would rapidly recognize this "peculiar mode of incidence.....well known in connexion with some other conditions" as a classic description of a recessive monogenic disorder.

Monogenic disorders arise due to carriage of highly penetrant variants affecting a single gene. The presence or absence of disease can be predicted from the presence or absence of the variant(s) of interest. With some allowance for differential penetrance and expressivity, the mathematical and predictable inheritance patterns of monogenic disorders enable meaningful genetic counseling to affected individuals and known carriers and to parents with a child affected by a de novo dominant mutation. Monogenic disorders are individually rare but cumulatively affect $1 \%$ of the worldwide population (3) and include many (currently, 461 defined) skeletal disorders (4).

\section{MAPPING RARE GENETIC DISORDERS: EARLY DAYS}

It took many decades to move from the recognition of monogenic disorders to the mapping of the first gene. Initially, such genes were mapped by linkage-the co-segregation [or linkage] of a genetic region with a disease phenotype within a family. The first disease to be linked to the inheritance of any genetic marker was the dominant disorder of Huntington's disease, initially mapped to the short arm of chromosome 4 in 1983 (5). However, it took another decade until the gene itself (huntingtin, located on chromosome 4p16.3) was finally determined, which effort took 58 researchers from six research groups and the participation of 75 large Venezuelan families (6). By this time, though, the first gene to be identified for any human disease had been cloned [CYBB, for X-linked chronic granulomatous disease (IM 300640)] (7). Linkage was often aided by recognition of chromosomal aberrations, such as translocation or uniparental disomy, in an affected individual -for example, contributing to the mapping of the gene for cystic fibrosis $(8,9)$. By 1995 a review article enthused about the dizzying number of genes which had been identified for human diseases - 42! - marking the only time the authors have seen the phrase, "Bingo!" used in a scientific paper (10).

Gene mapping by linkage, irrespective of the chosen marker [whether chromosomal banding patterns, restriction fragment length polymorphisms, microsatellites, or single nucleotide polymorphisms (SNPs)] is critically restricted by the number of informative meioses within contributing family pedigrees. Crossover events and recombination at meiosis incrementally limit the genetic region shared by affected individuals within the family; ergo, large multi-generational families with many affected individuals (equating to multiple meiotic events between distantly related affected individuals) represent the ideal pedigree for gene mapping via linkage. It would be unusual for a single pedigree to have sufficient affected individuals and sufficient informative meioses for definitive statistical evidence of linkage; thus, methods of summing genetic information from multiple families were developed. Many monogenic diseases were mapped by linkage, by 2001, 1,336 monogenic disorders [personal correspondence from Dr Victor McKusick, quoted in (11)].

There are some obvious difficulties with gene mapping by linkage. The first is that diseases with late onset or incomplete penetrance are harder to map, as correct disease attribution is more difficult. Large family pedigrees are inherently unlikely in diseases that adversely affect reproductive fitness (which includes many skeletal dysplasias, for example). The success of pooling genetic information from disparate families assumes that all affected individuals, irrespective of which family they come from, have a mutation in the same causative gene and not, for example, mutations in many different genes along a common pathway resulting in a common end phenotype. Here it is relevant to add that within any one family all affected individuals need to carry the same mutation (and, by definition, share the same haplotype of genetic markers); however, when pooling genetic information from multiple families, each family can have a different causative mutationas long as it is in the same gene. Diseases with significant gene/ environment interaction will be difficult to map-unless all family members are exposed equally to the requisite environment, essentially removing its contribution to variable affection status. Lastly, novel mutations are intractable by linkage, as by definition linkage requires the presence of a shared genetic haplotype among affected family members.

\section{MAPPING RARE GENETIC DISORDERS: A COMPLETE FRAMESHIFT}

In 2014, in a paper celebrating the $10^{\text {th }}$ anniversary of the release of the Human Genome (12) and using the example of gene mapping for fibrodysplasia ossificans progressiva (FOP; MIM 135100), we wrote that, "if massively parallel sequencing [MPS] technologies had been available when the search for the FOP gene began, the answer could have been found in 15 weeks, not 15 years." At first glance, this statement might seem excessively hubristic even for a celebratory piece. However, to illustrate the point: at this time we had just published a review of MPS in skeletal dysplasias (13) which 
at the time of submission (April 2013) listed 22 skeletal dysplasias mapped using MPS with a total of 26 publications; at the time of acceptance just twelve weeks later (July 2013) ten more papers had added another six skeletal dysplasia genes to the list. The Nosology and Classification of Genetic Skeletal Disorders: 2010 Revision identified "456 conditions...316 [of which] were associated with mutations in one or more of 226 different genes." (14) By the 2019 revision, pathogenic variants in 437 genes had been identified for 425 of 461 disorders now categorized (92\%) (4)-i.e. after the decades needed to identify the first 226 genes for rare skeletal disorders, it took less than 10 years to double this number. As for skeletal dysplasias, so for many other monogenic disorders, as the mode of gene discovery rapidly transitioned from positional cloning and other traditional gene mapping methods to MPS $(15,16)$. Currently, the catalog Online Mendelian Inheritance in Man (https://omim.org/) lists 6,751 phenotypes for which the molecular basis is known and 4,339 genes with a phenotypecausing mutation-these numbers have increased even during the short time this paper was in review.

The key developments underpinning the extraordinary recent progress in gene mapping in rare disorders are:

a. the publication of the human genome project in 2003 (17) (https://www.genome.gov/human-genome-project), providing the reference genome for comparison with sequence data.

b. the development of massively parallel sequencing (MPS) technologies-both undifferentiated genome sequencing and sequencing targeted to the exome or a defined set of genesallowing sequencing of multiple genomic regions simultaneously.

c. easy accessibility of large databases of genetic variability (such as the UK10K (https://www.uk10k.org/), 1,000Genomes (https://www.internationalgenome.org/), Human Variome Project (https://www.humanvariomeproject.org/), gnomAD (https://gnomad.broadinstitute.org/) and dbSNP (https:// www.ncbi.nlm.nih.gov/snp/), so that rare/novel diseasecausing variants could be differentiated from more common polymorphisms within ethnically appropriate populations.

d. international collaboration and cooperation, between clinicians and researchers, with interaction through platforms such as the National institute of Health Centers for Mendelian Genomics (http://mendelian.org/), Orphanet (https://www.orpha.net/ consor/cgi-bin/index.php), ClinVar (https://www.ncbi.nlm.nih. gov/clinvar/), Human Gene Mutation Database (http://www. hgmd.cf.ac.uk/ac/index.php), the International Rare Diseases Research Consortium (https://irdirc.org/) and Leiden Open Variation Database (https://www.lovd.nl/), informing and encouraging collaborative new gene discovery.

Each of the above websites has detailed information about their formation and governance.

\section{TYPES OF MASSIVELY PARALLEL SEQUENCING}

MPS technologies can be divided into pre-defined gene panels and the more agnostic approaches of whole genome and whole exome sequencing (with abbreviations WGS and WES respectively). The authors acknowledge that, strictly speaking, WGS and WES are misnomers, as neither technology has perfect coverage of its eponymous target; however, these common abbreviations will be used in this review. There are many excellent review articles on the technical aspects of the various types of MPS $(18,19)$. The strengths and weakness of different MPS technologies for new gene discovery and for clinical utility are discussed below.

\section{ANALYSIS OF MPS DATA}

Human genetic variability is huge. On average, each individual harbors 3 million SNPs (5,000 private to that individual); 700,000 indels (295 private), 215 large deletions (one private), and 576 genes with either homozygous or compound heterozygous predicted lossof-function variants (20). Sifting so much data to determine the causal variant for a disease can be, at the risk of understatement, challenging. After stringent quality control of the sequencing data, a typical common-sense and empiric approach adopted by ourselves and many others has been to filter for rare variants (with minor allele frequency thresholds informed by disease frequency and mode of inheritance) of likely deleterious effect (e.g., nonsense, missense, affecting canonical splice-sites, frameshift), affecting highly evolutionarily conserved bases and predicted damaging by one or more in silico prediction algorithms [e.g., SIFT (21), Polyphen (22), MutationTaster (23)] that segregate appropriately with disease within a family (24); or, if looking at unrelated individuals, are present in the same gene in multiple unrelated cases (25). Obviously this description is somewhat simplistic, and simply finding variants that fulfil these criteria does not prove they are disease-causing. However, these steps usually lead to a tractable list of variants that can then be assessed for functional consequence and/or compared with data from other unrelated individuals with a common phenotype.

The use of ethnically appropriate populations to determine allele frequencies for variants and inform their categorization as novel, rare, infrequent, or common, is critical. The reference data in most sequencing databases are not populated from all ethnic groups equally, with over-representation of western European Caucasian populations; more recent sequencing efforts have aimed to address this imbalance. Cohorts such as gnomAD (26) provide ethnicity-specific minor allele frequencies; but the robustness of these understandably depends on the size of the sequenced population contributing to the data.

\section{HOW MANY CASES ARE NEEDED TO MAP A MONOGENIC DISORDER?}

The success rate of MPS to map novel causative genes depends on the mode of inheritance of the condition. We have focused on examples drawn from skeletal dysplasias here, but the principles apply to other disease groups also.

Autosomal recessive disorders are generally easier to 'solve' as the list of genes with rare homozygous or compound 
heterozygous variants is usually relatively short. It is possible to identify the likely causative gene from initial sequencing a single affected individual (27-29) - though, as above, such evidence would need confirmation by identifying pathogenic variants in the same gene in other unrelated individuals and/or functional support.

For de novo dominant disorders, the causative gene may be mapped by sequencing a single affected child and parents (30) or by sequencing several unrelated probands (as few as three) and filtering the data for either a common variant shared by all affected individuals $(31,32)$ or with unique mutations but within a common gene $(25,33)$. Mapping inherited (as opposed to de novo) autosomal dominant diseases is more difficult due to coinheritance of multiple unimportant variants within a family. The most parsimonious design is to sequence most distantly related affected individuals: as discussed above, these have the largest number of meioses (and, by implication, greatest number of recombination events) separating the affected cases. With $n$ meioses between individuals, the chance of any given variant segregating is $(1 / 2)^{\mathrm{n}}$; and use of MPS data from both affected and unaffected individuals can help filter down variants according to disease status. Examples of autosomal dominant skeletal dysplasias mapped within a single family include spondylocostal dysostoses, mapped through MPS of five members of a family (three affected, two unaffected), with pathogenicity subsequently confirmed with functional data (34); and KBG syndrome [MIM 148050] (named after the initials of early affected individuals, in whom skeletal features include macrodontia, craniofacial abnormalities, and short stature), initially mapped through MPS of two affected family members and confirmed through MPS of one unrelated person (35).

Examples of X-linked skeletal dysplasias mapped by WES include the identification of mutations in FLNA as the cause of Terminal Osseous Dysplasia (36); and two forms of osteogenesis imperfecta, due to mutations in PLS3 (37) and MBTBS2 (38).

Somatic disorders can be mapped through paired analysis, with MPS of affected and unaffected tissues, subtracting the variants in the latter from the former-indeed, this approach is commonly employed in paired tumor/germline sequencing in cancer. This approach has been successful in skeletal dysplasias also-for example, identification of postzygotic somatic mutations in PIK3CA as the cause of Congenital Lipomatous Overgrowth with Vascular, Epidermal, and Skeletal anomalies (CLOVES), identified through WES of affected lipomatous tissue from six individuals compared with their germline DNA (39); and of AKT1 as the cause of Proteus Syndrome (40) through WES of affected $v$ s. unaffected tissue biopsies in 29 individuals. Depth of coverage will critically affect the ability to detect mosaicism, in that the allelic 'mix' in somatic disorders will vary both between individuals and between different tissues within an individual. The acceptable depth of MPS for calling germline heterozygous carriage of a variant is relatively modest: $10 \times$ is usually regarded as sufficient to 'call' a heterozygous variant and $15 \times$ for a homozygous variant (41); at these depths of coverage WES would be unlikely to detect low level mosaicism.

\section{STRENGTHS AND WEAKNESS OF DIFFERENT MPS TECHNOLOGIES FOR NEW GENE DISCOVERY AND FOR CLINICAL UTILITY}

In keeping with early predictions that $85 \%$ of Mendelian disorders would arise from coding mutations (42) and with the logic inherent in Sutton's law (viz., that one robs banks because that's where the money is), it is neither surprising that WES has been the most frequently employed modality to map novel genes, nor how successful this approach has been. Most of the examples provided above used WES as their mode of gene discovery, and the figure given above may well prove an underestimate. WES is not simply much cheaper than WGS for a given coverage: the large databases detailing exonic variation that informs analysis of WES data do not as yet exist for the whole genome (though this is rapidly changing with initiatives such as the UK Biobank 500K Sequencing Project and gnomAD), and proving causality for non-coding variants is difficult.

WES has proven similarly fruitful in diagnostic yield when translated from the research setting to clinical delivery [recently reviewed extensively (43)] with high diagnostic rates reported in both developed and developing countries (44), including sequencing in consanguineous families (44-46) and singleton sequencing (47) [noting that yield is approximately two-fold higher when sequencing parent-child trios compared with singletons (43)]. WES may also lead to a revision of a diagnosis-which may be confronting to both patient and clinician (discussed further below) but hopefully direct more appropriate clinical care $(45,47)$. A recent study reporting 155 novel causal genes identified during clinical sequencing (WES) in a consanguineous cohort comprising 2,200 families highlighted not only the use of WES for diagnostic purposes but also the benefits of these data in completing the virtuous circle of clinical discovery and clinical delivery, through feedback of these data for ongoing research and gene discovery (44). However, WES is not ideal for detection of copy number variation (48) including detection of large indels.

Very few monogenic disorders due to non-coding/splice-site variants have been identified to date (49). Ironically, a notable exception to this is the skeletal disorder of van Buchem's disease, a high bone mass disorder due to a $52 \mathrm{~kb}$ deletion downstream of SOST (50), though this disorder was not identified through MPS approaches. Thus, the usefulness of WGS in gene discovery in monogenic disorders, compared to WES, has not yet been established. Certainly WGS captures the exome more evenly (as well, obviously, as the genome) than does WES. WGS is also superior for the detection of large ( $>50 \mathrm{bp}$ ) indels, copy number variation, and chromosomal rearrangements. The higher costs of WGS and analysis are rapidly falling (51); and thus choosing between sequencing technologies from a purely fiscal perspective may soon be redundant. Nonetheless, to date WGS has not demonstrated superiority to WES in diagnostic utility (43); and the extent to which WGS may ultimately provide a diagnosis in cases for which WES has failed to identify a cause is not known. 
By definition, a targeted panel approach cannot be used for new gene discovery, as such panels consist of already identified genes. Nonetheless, panel sequencing has an established place within clinical delivery as a cheap, sensitive, and specific means of sequencing known disease genes, with excellent coverage due to the limited targeted region, and minimization of some of the concerns raised with the agnostic approaches such as WES or WGS such as incidental or secondary findings (discussed below). However, the first-line use of WES, rather than panel approaches - even when up to three panels were chosen by expert clinical geneticists-shortens the diagnostic odyssey and is more costeffective (52).

Considering clinical utility of MPS technologies for bone diseases specifically, both WES (53) and panel sequencing (54) approaches have been reported. There are no inherently unique issues pertaining to clinical use of MPS in skeletal diseases compared to other disorders.

\section{INCORRECT ATTRIBUTION OF PATHOGENICITY}

A variant is only rare when considered against the population; within a family, a rare variant is not rare-it has a $50 \%$ chance of transmission from a parent to a child; similarly siblings will share a variant identical-by-descent on average $50 \%$. It is extremely easy to be tempted into attributing causality to a rare variant that segregates within a small family just because it is rare [discussed in depth in (55) and (56)]. However, a priori one can predict the chance that any particular variant will segregate with disease within a family according to the number of meiosis between affected individuals and within a small family that probability may be higher than the typical threshold for declaring scientific significance (i.e. $\mathrm{p}<0.05$ ). Unsurprisingly, in a review article on this topic, MacArthur et al. wrote that of "406 published severe disease mutations...122 (27\%) were either common polymorphisms or lacked direct evidence for pathogenicity" (56).

Efforts to refine criteria for attributing pathogenicity to an identified variant led to the publication of guidelines for classifying the likely pathogenicity of identified variants (e.g. 'pathogenic', 'likely pathogenic', 'variants of uncertain significance', etc.) according to the strength of evidence (57). These guidelines recommend using multiple criteria and resources to guide classification of an individual variant into a particular category, including population, disease-specific, and sequence databases, the published literature, the type of variant (nonsense, frameshift, initiation codon, canonical splice-sites, large deletions, etc.), and in silico prediction algorithms. However, considering the evidential basis even within these criteria demonstrates the imperfections. There are multiple in silico prediction methods, each with differing criteria (gene-level, variant level, evolutionary conservation, amino acid change, etc.) trained on varying datasets-not surprisingly, they vary in performance [recently discussed and compared in (58)]. Replication-observing the same mutation with the same phenotype in an unrelated family-depends on cooperation and collaboration of researchers, and for rare diseases this needs to happen at an international level-which depends on clinical networks. Clinical variation databases (e.g., ClinVar, Online Mendelian Inheritance in Man, Leiden Open Variation Database, Human Gene Mutation Database) rely on curation expertise. Altruism is a key component for the success of any database [including PubMed (https://pubmed.ncbi.nlm.nih.gov/)] - however, clinical reporting of affected cases requires awareness, motivation, confidence, and time. Thus, functional studies, in either in vitro or in vivo models, are often necessary for definitive classification. To this end, CRISPR technology (for which discoverers Emmanuelle Charpentier and Jennifer Doudna were recently awarded the 2020 Nobel Prize for Chemistry) has proven a boon.

\section{ETHICAL, LEGAL, AND SOCIAL IMPLICATIONS IN MASSIVELY PARALLEL SEQUENCING TECHNOLOGIES}

Whatever type of genetic testing is performed-whether MPS or other technologies-pre-test discussion is crucial to ensure the individual is aware of all possible outcomes and their implications, both for the individual personally and for their family members. Some considerations are universally longrecognized risks associated with any type of genetic test (discussed further below). However, MPS can add to the magnitude of risk and/or complexity of results, as well as generating issues specific to the technology, such as secondary findings.

\section{Relationship Misattribution}

For decades, clinical genetics professionals have faced the challenge of misattributed relationships identified through genetic testing, especially non-paternity. Most genetics clinicians only disclose this information when clinically necessary $(59,60)$. Moreover, in accordance with the Institute of Medicine Guidelines (61), non-paternity results [estimated to be present in up to $30.0 \%$ of livebirths (62)] are only disclosed to the mother alone. With genetic tests ordered in many more settings and much more frequently, the risk of uncovering misattributed relationships is extremely likely to increase (63). In addition, misattributed relationship results generated by single-gene tests are often associated with some degree of uncertainty, which allows for some degree of clinical discretion. In contrast, the simultaneous identification of both common and rare variants inherent in any MPS technology generates unequivocal results (63).

\section{Disclosure of Genetic Status Through Relationships With Other Family Members}

The shared nature of genetic material means that a positive test result in one individual can reveal the genetic status of other family members by inference. This may be due to their affection 
status (e.g., a BRCA1 result in a woman with breast cancer implies mutation carriage in her mother with ovarian cancer) or the nature of inheritance (e.g., the obligate carrier status of parents whose child is diagnosed with a recessive condition).

\section{Unexpected Results Related to the Disease in Question}

Genetic tests have the potential to yield information about the future health of an individual, who may be clinically unaffected at the time of testing. In single gene testing for carrier status, careful predisposition testing protocols were developed, particularly for neurodegenerative (64) and cancer susceptibility syndromes (65), to ensure individuals were prepared for the clinical, psychological, and logistical sequelae of learning such information. Preparing an individual for testing by MPS is challenging from a counseling perspective, if only for the large number of genes being tested simultaneously. However, more subtle issues may arise-for example, a causal gene may be identified that differs from the expected gene (66); and the results may confer an increased risk for conditions not previously described in the family or not previously recognized to be significant (e.g., a TP53 mutation in a family with a strong history of breast cancer).

\section{Variants of Uncertain Significance}

Variants of uncertain significance (VUSs) are variants for which there is insufficient evidence to classify them as benign or pathogenic. As additional information becomes available over time, they are sometimes re-classified as pathogenic/likely pathogenic or, more commonly, benign/likely benign (67-69). VUSs have been a long-standing challenge in genetic testing for hereditary cancer generally (68) and BRCA1/2 specifically (67). The larger the number of genes interrogated, the higher the probability of generating a VUS: 36 and $73 \%$ in multigene panels (70) and exome sequencing (71) respectively. A recent systematic review found VUSs are associated with genetic test-specific concern and affects clinical management (72).

\section{Incidental or Secondary Findings}

Incidental or secondary findings are genetic test results unrelated to the primary condition. Incidental findings are generally regarded to be inadvertent or accidental discoveries emerging during data analysis. In contrast, secondary findings emerge from the deliberate interrogation of 'actionable' genes in individuals undergoing WES or WGS, with the goal of prevention or early detection of treatable conditions. To overcome the challenge of terminology, these are cumulatively referred to as incidental and secondary findings (ISFs) (73).

In 2013, the American College of Medical Genetics published guidelines recommending that all individuals having WES/WGS have automatic analysis of 56 actionable genes, associated with 24 hereditary cardiac or cancer predisposition syndromes (74). Among other statements, the guidelines stated that neither patient age nor patient preferences should be taken into account because this would be "logistically challenging" for laboratories (74). The paper stimulated multiple articles in response. Concerns raised included the lack of scientific evidence to support screening of all 56 genes, with insufficient information about phenotype and penetrance $(75,76)$. The potential for large numbers of VUSs was also recognized as was the challenge of interpreting variants in ethnic minorities (77). The potential for iatrogenic harm or false reassurance was raised. Multiple papers stated that the guidelines disregarded individual autonomy $(78,79)$ and contravened the ACMG's own guidelines on genetic testing in children (75) - with overlapping concerns of lack of informed consent (75). The second version of the guidelines removed the wording around any obligation to interrogate these genes whenever WES/WGS and acknowledged that all patients should have the right to opt out-and modified the medically actionable genes to a slightly different list with the overall number increased to 59 (80). At present, some laboratories offer secondary screening of the ACMG 59 ${ }^{\mathrm{TM}}$ (81); however, the extent to which it has been adopted by clinical laboratories world-wide is unclear. Additionally, there is ongoing debate about whether the ACMG $59^{\mathrm{TM}}$ should be offered and reported in the prenatal period (82). The ACMG Board of Directors recently released a policy statement stating that they do not support the use of ACMG $59^{\mathrm{TM}}$ as a screening tool in the general population (83).

\section{Genetic Discrimination}

Fear of genetic discrimination, particularly as it pertains to insurance underwriting, is a deterrent in the pursuit of clinically indicated genetic testing (84-86). Several papers suggest these fears are not ill-founded, with incidences of proven or alleged genetic discrimination reported in carriers of recessive conditions (87-89) and-perhaps surprisinglyindividuals receiving a negative (i.e. good news) result in predictive testing for familial mutations $(88,89)$ and healthy carriers of dominant variants who pursued surgical/medical interventions and/or screening to mitigate their risk (89-96). Policies and legislation have been introduced in many countries (including the UK, US, Canada, Australia, and European countries) to limit or prohibit the use of genetic test results in insurance underwriting (97), but initial studies suggest that awareness of such legislation among non-genetics clinicians (98) and members of the public $(99,100)$ is low. For example, a UK study found that BRCA1/2 carriers had difficulty obtaining insurance even after the introduction of the Concordat and Moratorium on Genetics and Insurance (95).

\section{Equity}

Personalized (or precision) medicine aims to improve care by customizing management to the individual and the profile of their disease. Genetic testing is an integral component of personalized medicine and encompasses a gamut of approaches, from tumor sequencing [e.g., improving survival through targeted chemotherapy (101)] to common variant genotyping [e.g., use of polygenic risk scores, usually determined through microarray technology (102)] to rare variant detection by MPS technologies (as discussed above). Access to genetic services is limited by racial, ethnic, and social factors; and disproportionate access has potential to widen, rather than reduce, health disparities both within developed countries $(103,104)$ and 
between developed and developing countries (105) [though here we would highlight increasing use of MPS technologies clinically in communities with higher rates of intrafamilial marriage (44-46)].

\section{FINAL THOUGHTS: ACCESS TO SEQUENCING AND FUTURE DIRECTIONS}

In 2016, one of the current authors wrote "Conventional sequencing is commercially available for a finite number of mutations in clear-cut monogenic diseases-but these conditions represent a minority of genetic disorders. In Australia, genetic testing is available for 597 genes which cause $<500$ different syndromes and conditions, a small subset of the $\sim 5,000$ " [McInerney-Leo, PhD thesis; data drawn from the Royal College of Pathologists, Australia, accessed 2016 (http:// genetictesting.rcpa.edu.au)]. Just four years later, the situation is very different, with both public and private access to testing for multiple conditions in Australia and in many countries around the world. A recent review article led with an arresting title of $A$

\section{REFERENCES}

1. Garrod AE. The incidence of alkaptonuria: a study in chemical individuality. 1902. Mol Med (Cambridge Mass) (1996) 2(3):274-82. doi: 10.1007/ BF03401625

2. Mendel JG. "Versuche über Pflanzenhybriden", Verhandlungen des naturforschenden Vereines in Brünn, Bd. IV für das Jahr, 1865, Abhandlungen: 3-47. For the English translation, see: Druery, C.T.; Bateson, William (1901). "Experiments in plant hybridization". J R Hortic Society (1866) 26:1-32.

3. World Health Organisation. Human Genomics in Global Health: Genes and human diseases (2020). Available at: https://www.who.int/genomics/public/ geneticdiseases/en/index2.html.

4. Mortier GR, Cohn DH, Cormier-Daire V, Hall C, Krakow D, Mundlos S, et al. Nosology and classification of genetic skeletal disorders: 2019 revision. Am J Med Genet A (2019) 179(12):2393-419. doi: 10.1002/ajmg.a.61366

5. Gusella JF, Wexler NS, Conneally PM, Naylor SL, Anderson MA, Tanzi RE, et al. A polymorphic DNA marker genetically linked to Huntington's disease. Nature (1983) 306(5940):234-8. doi: 10.1038/306234a0

6. Group THsDCR. A novel gene containing a trinucleotide repeat that is expanded and unstable on Huntington's disease chromosomes. Cell (1993) 72(6):971-83. doi: 10.1016/0092-8674(93)90585-E

7. Royer-Pokora B, Kunkel LM, Monaco AP, Goff SC, Newburger PE, Baehner $\mathrm{RL}$, et al. Cloning the gene for an inherited human disorder-chronic granulomatous disease-on the basis of its chromosomal location. Nature (1986) 322(6074):32-8. doi: 10.1038/322032a0

8. Voss R, Ben-Simon E, Avital A, Godfrey S, Zlotogora J, Dagan J, et al. Isodisomy of chromosome 7 in a patient with cystic fibrosis: could uniparental disomy be common in humans? Am J Hum Genet (1989) 45 (3):373-80. doi: 10.1016/0168-9525(89)90184-4

9. Kerem B, Rommens JM, Buchanan JA, Markiewicz D, Cox TK, Chakravarti A, et al. Identification of the cystic fibrosis gene: genetic analysis. Science (1989) 245(4922):1073-80. doi: 10.1126/science.2570460

10. Collins FS. Positional cloning moves from perditional to traditional. Nat Genet (1995) 9(4):347-50. doi: 10.1038/ng0495-347

11. Glazier A, Nadeau J, Aitman T. Finding genes that underlie complex traits. Science (2002) 298:2345-50. doi: 10.1126/science.1076641

12. Duncan E, Brown M, Shore EM. The revolution in human monogenic disease mapping. Genes (2014) 5(3):792-803. doi: 10.3390/genes5030792
Diagnosis for All Rare Genetic Diseases: the Horizon and the Next Frontiers, (49) and presented a vision that all families with a rare genetic disorder would ultimately receive a genetic diagnosis through sequencing technologies and novel data analyses approaches. This aim is not only exciting but with ongoing international cooperation and collaboration-even midcoronavirus-it also seems achievable (49).

\section{AUTHOR CONTRIBUTIONS}

Both AM-L and ED prepared and reviewed this manuscript. All authors contributed to the article and approved the submitted version.

\section{FUNDING}

AM-L is funded by a National Health and Medical Research Council (NHMRC) Early Career Fellowship (ID 1158111).

13. Lazarus S, Zankl A, Duncan EL. Next-generation sequencing: a frameshift in skeletal dysplasia gene discovery. Osteoporosis Int J established as result cooperation between Eur Foundation Osteoporosis Natl Osteoporosis Foundation USA (2014) 25(2):407-22. doi: 10.1007/ s00198-013-2443-1

14. Warman ML, Cormier-Daire V, Hall C, Krakow D, Lachman R, LeMerrer M, et al. Nosology and classification of genetic skeletal disorders: 2010 revision. Am J Med Genet A (2011) 155A(5):943-68. doi: 10.1002/ajmg.a.33909

15. Chong JX, Buckingham KJ, Jhangiani SN, Boehm C, Sobreira N, Smith JD, et al. The Genetic Basis of Mendelian Phenotypes: Discoveries, Challenges, and Opportunities. Am J Hum Genet (2015) 97(2):199-215. doi: 10.1016/ j.ajhg.2015.06.009

16. Boycott KM, Rath A, Chong JX, Hartley T, Alkuraya FS, Baynam G, et al. International Cooperation to Enable the Diagnosis of All Rare Genetic Diseases. Am J Hum Genet (2017) 100(5):695-705. doi: 10.1016/ j.ajhg.2017.04.003

17. Collins FS, Green ED, Guttmacher AE, Guyer MS. A vision for the future of genomics research. Nature (2003) 422(6934):835-47. doi: 10.1038/ nature 01626

18. McCombie WR, McPherson JD, Mardis ER. Next-Generation Sequencing Technologies. Cold Spring Harbor Perspect Medicine (2019) 9(11):a036798. doi: $10.1101 /$ cshperspect.a036798

19. van Dijk EL, Auger H, Jaszczyszyn Y, Thermes C. Ten years of nextgeneration sequencing technology. Trends Genet TIG (2014) 30(9):418-26. doi: 10.1016/j.tig.2014.07.001

20. Walter K, Min JL, Huang J, Crooks L, Memari Y, McCarthy S, et al. The UK10K project identifies rare variants in health and disease. Nature (2015) 526(7571):82-90. doi: 10.1038/nature14962

21. Vaser R, Adusumalli S, Leng SN, Sikic M, Ng PC. SIFT missense predictions for genomes. Nat Protoc (2016) 11(1):1-9. doi: 10.1038/nprot.2015.123

22. Adzhubei IA, Schmidt S, Peshkin L, Ramensky VE, Gerasimova A, Bork P, et al. A method and server for predicting damaging missense mutations. Nat Methods (2010) 7(4):248-9. doi: 10.1038/nmeth0410-248

23. Schwarz JM, Cooper DN, Schuelke M, Seelow D. MutationTaster2: mutation prediction for the deep-sequencing age. Nat Methods (2014) 11(4):361-2. doi: $10.1038 /$ nmeth. 2890

24. McInerney-Leo AM, Le Goff C, Leo PJ, Kenna TJ, Keith P, Harris JE, et al. Mutations in LTBP3 cause acromicric dysplasia and geleophysic dysplasia. J Med Genet (2016) 53(7):457-64. doi: 10.1136/jmedgenet-2015-103647 
25. Zankl A, Duncan EL, Leo PJ, Clark GR, Glazov EA, Addor MC, et al. Multicentric Carpotarsal Osteolysis Is Caused by Mutations Clustering in the Amino-Terminal Transcriptional Activation Domain of MAFB. Am J Hum Genet (2012) 90(3):494-501. doi: 10.1016/j.ajhg.2012.01.003

26. Karczewski KJ, Francioli LC, Tiao G, Cummings BB, Alföldi J, Wang Q, et al. The mutational constraint spectrum quantified from variation in 141,456 humans. Nature (2020) 581(7809):434-43. doi: 10.1530/ey.17.14.3

27. Bredrup C, Saunier S, Oud MM, Fiskerstrand T, Hoischen A, Brackman D, et al. Ciliopathies with skeletal anomalies and renal insufficiency due to mutations in the IFT-A gene WDR19. Am J Hum Genet (2011) 89(5):63443. doi: 10.1016/j.ajhg.2011.10.001

28. Becker J, Semler O, Gilissen C, Li Y, Bolz HJ, Giunta C, et al. Exome sequencing identifies truncating mutations in human SERPINF1 in autosomal-recessive osteogenesis imperfecta. Am J Hum Genet (2011) 88 (3):362-71. doi: 10.1016/j.ajhg.2011.01.015

29. McInerney-Leo AM, Schmidts M, Cortés CR, Leo PJ, Gener B, Courtney $\mathrm{AD}$, et al. Short-rib polydactyly and Jeune syndromes are caused by mutations in WDR60. Am J Hum Genet (2013) 93(3):515-23. doi: 10.1016/j.ajhg.2013.06.022

30. Semler O, Garbes L, Keupp K, Swan D, Zimmermann K, Becker J, et al. A Mutation in the 5'-UTR of IFITM5 Creates an In-Frame Start Codon and Causes Autosomal-Dominant Osteogenesis Imperfecta Type V with Hyperplastic Callus. Am J Hum Genet (2012) 91(2):349-57. doi: 10.1016/ j.ajhg.2012.06.011

31. Rauch F, Moffatt P, Cheung M, Roughley P, Lalic L, Lund AM, et al. Osteogenesis imperfecta type V: marked phenotypic variability despite the presence of the IFITM5 c.-14C $>\mathrm{T}$ mutation in all patients. J Med Genet (2013) 50(1):21-4. doi: 10.1136/jmedgenet-2012-101307

32. Wade EM, Wade EM, Daniel PB, Jenkins ZA, McInerney-Leo A, Leo P, Morgan T, et al. Mutations in MAP3K7 that Alter the Activity of the TAK1 Signaling Complex Cause Frontometaphyseal Dysplasia. Am J Hum Genet (2016) 99(2):392-406. doi: 10.1016/j.ajhg.2016.05.024

33. Simpson MA, Irving MD, Asilmaz E, Gray MJ, Dafou D, Elmslie FV, et al. Mutations in NOTCH2 cause Hajdu-Cheney syndrome, a disorder of severe and progressive bone loss. Nat Genet (2011) 43(4):303-5. doi: 10.1038/ng.779

34. Sparrow DB, McInerney-Leo A, Gucev ZS, Gardiner B, Marshall M, Leo PJ, et al. Autosomal dominant spondylocostal dysostosis is caused by mutation in TBX6. Hum Mol Genet (2013) 22(8):1625-31. doi: 10.1093/hmg/ddt012

35. Sirmaci A, Spiliopoulos M, Brancati F, Powell E, Duman D, Abrams A, et al. Mutations in ANKRD11 cause KBG syndrome, characterized by intellectual disability, skeletal malformations, and macrodontia. Am J Hum Genet (2011) 89(2):289-94. doi: 10.1016/j.ajhg.2011.06.007

36. Sun Y, Almomani R, Aten E, Celli J, van der Heijden J, Venselaar H, et al. Terminal osseous dysplasia is caused by a single recurrent mutation in the FLNA gene. Am J Hum Genet (2010) 87(1):146-53. doi: 10.1016/j.ajhg.2010.06.008

37. van Dijk FS, Zillikens MC, Micha D, Riessland M, Marcelis CL, de DieSmulders CE, et al. PLS3 mutations in X-linked osteoporosis with fractures. N Engl J Med (2013) 369(16):1529-36. doi: 10.1056/NEJMoa1308223

38. Lindert U, Cabral WA, Ausavarat S, Tongkobpetch S, Ludin K, Barnes AM, et al. MBTPS2 mutations cause defective regulated intramembrane proteolysis in X-linked osteogenesis imperfecta. Nat communications (2016) 7:11920. doi: 10.1038/ncomms11920

39. Kurek KC, Luks VL, Ayturk UM, Alomari AI, Fishman SJ, Spencer SA, et al. Somatic mosaic activating mutations in PIK3CA cause CLOVES syndrome. Am J Hum Genet (2012) 90(6):1108-15. doi: 10.1016/j.ajhg.2012.05.006

40. Lindhurst MJ, Sapp JC, Teer JK, Johnston JJ, Finn EM, Peters K, et al. A mosaic activating mutation in AKT1 associated with the Proteus syndrome. N Engl J Med (2011) 365(7):611-9. doi: 10.1056/NEJMoa1104017

41. Kong SW, Lee IH, Liu X, Hirschhorn JN, Mandl KD. Measuring coverage and accuracy of whole-exome sequencing in clinical context. Genet Med OffJ Am Coll Med Genet (2018) 20(12):1617-26. doi: 10.1038/gim.2018.51

42. Cooper DN KM, Antonorakis SE. The nature and mechanisms of human gene mutation. In: CBA Scriver, WS Sly, D Valle, editors. The Metabolic and Molecular Bases of Inherited Disease, 7th ed. New York: McGraw-Hill (1995). p. $259-91$.

43. Clark MM, Stark Z, Farnaes L, Tan TY, White SM, Dimmock D, et al. Metaanalysis of the diagnostic and clinical utility of genome and exome sequencing and chromosomal microarray in children with suspected genetic diseases. NPJ Genomic Medicine (2018) 3(1):16. doi: 10.1038/ s41525-018-0053-8

44. Monies D, Abouelhoda M, Assoum M, Moghrabi N, Rafiullah R, Almontashiri $\mathrm{N}$, et al. Lessons Learned from Large-Scale, First-Tier Clinical Exome Sequencing in a Highly Consanguineous Population. Am J Hum Genet (2019) 104(6):1182-201. doi: 10.1016/j.ajhg.2019.09.019

45. Cheema H, Bertoli-Avella AM, Skrahina V, Anjum MN, Waheed N, Saeed A, et al. Genomic testing in 1019 individuals from 349 Pakistani families results in high diagnostic yield and clinical utility. NPJ Genomic Medicine (2020) 5(1):44. doi: 10.1038/s41525-020-00150-Z

46. Alfares A, Alfadhel M, Wani T, Alsahli S, Alluhaydan I, Al Mutairi F, et al. A multicenter clinical exome study in unselected cohorts from a consanguineous population of Saudi Arabia demonstrated a high diagnostic yield. Mol Genet Metab (2017) 121(2):91-5. doi: 10.1016/ j.ymgme.2017.04.002

47. Stark Z, Tan TY, Chong B, Brett GR, Yap P, Walsh M, et al. A prospective evaluation of whole-exome sequencing as a first-tier molecular test in infants with suspected monogenic disorders. Genet Medicine (2016) 18(11):1090-6. doi: 10.1038/gim.2016.1

48. Yao R, Zhang C, Yu T, Li N, Hu X, Wang X, et al. Evaluation of three readdepth based $\mathrm{CNV}$ detection tools using whole-exome sequencing data. $\mathrm{Mol}$ Cytogenetics (2017) 10(1):30. doi: 10.1186/s13039-017-0333-5

49. Boycott KM, Hartley T, Biesecker LG, Gibbs RA, Innes AM, Riess O, et al. A Diagnosis for All Rare Genetic Diseases: The Horizon and the Next Frontiers. Cell (2019) 177(1):32-7. doi: 10.1016/j.cell.2019.02.040

50. Balemans W, Patel N, Ebeling M, Van Hul E, Wuyts W, Lacza C, et al. Identification of a $52 \mathrm{~kb}$ deletion downstream of the SOST gene in patients with van Buchem disease. J Med Genet (2002) 39(2):91-7. doi: 10.1136/ jmg.39.2.91

51. Mazzarotto F, Olivotto I, Walsh R. Advantages and Perils of Clinical WholeExome and Whole-Genome Sequencing in Cardiomyopathy. Cardiovasc Drugs Ther (2020) 34(2):241-53. doi: 10.1007/s10557-020-06948-4

52. Dillon OJ, Lunke S, Stark Z, Yeung A, Thorne N, Gaff C, et al. Exome sequencing has higher diagnostic yield compared to simulated diseasespecific panels in children with suspected monogenic disorders. Eur J Hum Genet (2018) 26(5):644-51. doi: 10.1038/s41431-018-0099-1

53. McInerney-Leo AM, Marshall MS, Gardiner B, Coucke PJ, Van Laer L, Loeys BL, et al. Whole exome sequencing is an efficient, sensitive and specific method of mutation detection in osteogenesis imperfecta and Marfan syndrome. BoneKEy Reports (2013) 2:456. doi: 10.1038/ bonekey.2013.190

54. Collet C, Ostertag A, Ricquebourg M, Delecourt M, Tueur G, Isidor B, et al. Primary Osteoporosis in Young Adults: Genetic Basis and Identification of Novel Variants in Causal Genes. JBMR Plus (2018) 2(1):12-21. doi: 10.1002/ jbm4.10020

55. Minikel EV, Vallabh SM, Lek M, Estrada K, Samocha KE, Sathirapongsasuti JF, et al. Quantifying prion disease penetrance using large population control cohorts. Sci Transl Med (2016) 8(322):322ra329. doi: 10.1126/ scitranslmed.aad5169

56. MacArthur DG, Manolio TA, Dimmock DP, Rehm HL, Shendure J, Abecasis GR, et al. Guidelines for investigating causality of sequence variants in human disease. Nature (2014) 508(7497):469-76. doi: 10.1038/ nature13127

57. Richards S, Aziz N, Bale S, Bick D, Das S, Gastier-Foster J, et al. Standards and guidelines for the interpretation of sequence variants: a joint consensus recommendation of the American College of Medical Genetics and Genomics and the Association for Molecular Pathology. Genet Med Off J Am Coll Med Genet (2015) 17(5):405-24. doi: 10.1038/gim.2015.30

58. Tian Y, Pesaran T, Chamberlin A, Fenwick RB, Li S, Gau CL, et al. REVEL and BayesDel outperform other in silico meta-predictors for clinical variant classification. Sci Reports (2019) 9(1):12752. doi: 10.1038/s41598-019-49224-8

59. Wertz DC, Fletcher JC. Privacy and disclosure in medical genetics examined in an ethics of care. Bioethics (1991) 5(3):212-32. doi: 10.1111/j.14678519.1991.tb00161.x

60. Wright L, MacRae S, Gordon D, Elliot E, Dixon D, Abbey S, et al. Disclosure of misattributed paternity: issues involved in the discovery of unsought information. Semin Dial (2002) 15(3):202-6. doi: 10.1046/j.1525139X.2002.00541.x 
61. Research PsCftSoEPiMaBaB. Screening and Counseling for Genetic Conditions: A Report on the Ethical, Social, and Legal Implications of Genetic Screening, Counseling, and Education Programs. Washington DC: The Government of the Unites States of America (1983).

62. Bellis MA, Hughes K, Hughes S, Ashton JR. Measuring paternal discrepancy and its public health consequences. J Epidemiol Community Health (2005) 59(9):749-54. doi: 10.1136/jech.2005.036517

63. Hercher L, Jamal L. An old problem in a new age: Revisiting the clinical dilemma of misattributed paternity. Appl Transl Genom (2016) 8:36-9. doi: 10.1016/j.atg.2016.01.004

64. Tibben A. Predictive testing for Huntington's disease. Brain Res Bull (2007) 72(2-3):165-71. doi: 10.1016/j.brainresbull.2006.10.023

65. Berg AO, Allan JD, Calonge N, Frame PS. Genetic risk assessment and BRCA mutation testing for breast and ovarian cancer susceptibility: Recommendation statement. Ann Internal Medicine (2005) 143(5):355-61. doi: 10.7326/0003-4819-143-5-200509060-00011

66. Christiaans I, Mook ORF, Alders M, Bikker H, Lekanne Dit Deprez RH. Large next-generation sequencing gene panels in genetic heart disease: challenges in clinical practice. Neth Heart J (2019) 27(6):299-303. doi: 10.1007/s12471-019-1251-4

67. Mighton C, Charames GS, Wang M, Zakoor KR, Wong A, Shickh S, et al. Variant classification changes over time in BRCA1 and BRCA2. Genet Med Off J Am Coll Med Genet (2019) 21(10):2248-54. doi: 10.1038/s41436-0190493-2

68. Mersch J, Brown N, Pirzadeh-Miller S, Mundt E, Cox HC, Brown K, et al. Prevalence of Variant Reclassification Following Hereditary Cancer Genetic Testing. JAMA (2018) 320(12):1266-74. doi: 10.1001/jama.2018.13152

69. Macklin S, Durand N, Atwal P, Hines S. Observed frequency and challenges of variant reclassification in a hereditary cancer clinic. Genet Med Off J Am Coll Med Genet (2018) 20(3):346-50. doi: 10.1038/gim.2017.207

70. Buys SS, Sandbach JF, Gammon A, Patel G, Kidd J, Brown KL, et al. A study of over 35,000 women with breast cancer tested with a 25-gene panel of hereditary cancer genes. Cancer (2017) 123(10):1721-30. doi: 10.1002/ cncr.30498

71. Dixon-Salazar TJ, Silhavy JL, Udpa N, Schroth J, Bielas S, Schaffer AE, et al. Exome sequencing can improve diagnosis and alter patient management. Sci Transl Med (2012) 4(138):138ra178. doi: 10.1126/scitranslmed.3003544

72. Mighton C, Shickh S, Uleryk E, Pechlivanoglou P, Bombard Y. Clinical and psychological outcomes of receiving a variant of uncertain significance from multigene panel testing or genomic sequencing: a systematic review and meta-analysis. Genet Med Off J Am Coll Med Genet (2020) 23(1):22-33. doi: 10.1038/s41436-020-00957-2

73. Saelaert M, Mertes H, De Baere E, Devisch I. Incidental or secondary findings: an integrative and patient-inclusive approach to the current debate. Eur J Hum Genet (2018) 26(10):1424-31. doi: 10.1038/s41431-0180200-9

74. Green RC, Berg JS, Grody WW, Kalia SS, Korf BR, Martin CL, et al. ACMG recommendations for reporting of incidental findings in clinical exome and genome sequencing. Genet Med Off J Am Coll Med Genet (2013) 15(7):56574. doi: 10.1038/gim.2013.73

75. Burke W, Antommaria AH, Bennett R, Botkin J, Clayton EW, Henderson $\mathrm{GE}$, et al. Recommendations for returning genomic incidental findings? We need to talk! Genet Med Off J Am Coll Med Genet (2013) 15(11):854-9. doi: 10.1038/gim.2013.113

76. Holtzman NA. ACMG recommendations on incidental findings are flawed scientifically and ethically. Genet Med Off J Am Coll Med Genet (2013) 15 (9):750-1. doi: 10.1038/gim.2013.96

77. Amendola LM, Dorschner MO, Robertson PD, Salama JS, Hart R, Shirts BH, et al. Actionable exomic incidental findings in 6503 participants: challenges of variant classification. Genome Res (2015) 25(3):305-15.

78. Ross LF, Rothstein MA, Clayton EW. Mandatory extended searches in all genome sequencing: "incidental findings," patient autonomy, and shared decision making. JAMA (2013) 310(4):367-8. doi: 10.1001/jama.2013.41700

79. Wolf SM, Annas GJ, Elias S. Point-counterpoint. Patient autonomy and incidental findings in clinical genomics. Science (2013) 340(6136):1049-50. doi: $10.1126 /$ science. 1239119

80. Kalia SS, Adelman K, Bale SJ, Chung WK, Eng C, Evans JP, et al. Recommendations for reporting of secondary findings in clinical exome and genome sequencing, 2016 update (ACMG SF v2.0): a policy statement of the American College of Medical Genetics and Genomics. Genet Med Off J Am Coll Med Genet (2017) 19(2):249-55. doi: 10.1038/gim.2017.17

81. Nussbaum RL, Haverfield E, Esplin ED, Aradhya S. Response to "The use of ACMG secondary findings recommendations for general population screening: a policy statement of the American College of Medical Genetics and Genomics (ACMG)". Genet Med Off J Am Coll Med Genet (2019) 21 (12):2836-7. doi: 10.1038/s41436-019-0572-4

82. Amor DJ, Chitty LS, Van den Veyver IB. Current controversies in prenatal diagnosis 2: The 59 genes ACMG recommends reporting as secondary findings when sequencing postnatally should be reported when detected on fetal (and parental) sequencing. Prenat Diagn (2020) 40(12):1508-14. doi: $10.1002 /$ pd. 5670

83. Directors ABo. The use of ACMG secondary findings recommendations for general population screening: a policy statement of the American College of Medical Genetics and Genomics (ACMG). Genet Med (2019) 21(7):1467-8. doi: 10.1038/s41436-019-0502-5

84. Joly Y, Ngueng Feze I, Simard J. Genetic discrimination and life insurance: a systematic review of the evidence. BMC Medicine (2013) 11:25. doi: 10.1186/ 1741-7015-11-25

85. Wauters A, Van Hoyweghen I. Global trends on fears and concerns of genetic discrimination: a systematic literature review. J Hum Genet (2016) 61 (4):275-82. doi: 10.1038/jhg.2015.151

86. Quinlivan JA, Battikhi Z, Petersen RW. What Factors Impact upon a Woman's Decision to Undertake Genetic Cancer Testing? Front Oncol (2014) 3:325. doi: 10.3389/fonc.2013.00325

87. Geller LN, Alper JS, Billings PR, Barash CI, Beckwith J, Natowicz MR. Individual, family, and societal dimensions of genetic discrimination: a case study analysis. Sci Eng Ethics (1996) 2(1):71-88. doi: 10.1007/BF02639319

88. Low L, King S, Wilkie T. Genetic discrimination in life insurance: empirical evidence from a cross sectional survey of genetic support groups in the United Kingdom. BMJ (1998) 317(7173):1632-5. doi: 10.1136/bmj.317.7173.1632

89. Barlow-Stewart K, Keays D. Genetic Discrimination in Australia. J L Med (2001) 8:250-62.

90. McKinnon W, Banks KC, Skelly J, Kohlmann W, Bennett R, Shannon K, et al, et al. Survey of unaffected BRCA and mismatch repair (MMR) mutation positive individuals. Fam Cancer (2009) 8(4):363-9. doi: 10.1007/s10689-009-9248-6

91. Otlowski M, Barlow-Stewart K, Taylor S, Stranger M, Treloar S. Investigating genetic discrimination in the Australian life insurance sector: the use of genetic test results in underwriting, 1999-2003. J Law Med (2007) 14(3):367-96.

92. Barlow-Stewart K, Taylor SD, Treloar SA, Stranger M, Otlowski M. Verification of consumers' experiences and perceptions of genetic discrimination and its impact on utilization of genetic testing. Genet Med Off J Am Coll Med Genet (2009) 11(3):193-201. doi: 10.1097/ GIM.0b013e318194ee 75

93. Keogh LA, Otlowski MF. Life insurance and genetic test results: a mutation carrier's fight to achieve full cover. Med J Aust (2013) 199(5):363-6. doi: 10.5694/mja13.10202

94. Tiller J, Morris S, Rice T, Barter K, Riaz M, Keogh L, et al. Genetic discrimination by Australian insurance companies: a survey of consumer experiences. Eur J Hum Genet (2020) 28(1):108-13. doi: 10.1038/s41431019-0426-1

95. Watson M, Foster C, Eeles R, Eccles D, Ashley S, Davidson R, et al, et al. Psychosocial impact of breast/ovarian (BRCA1/2) cancer-predictive genetic testing in a UK multi-centre clinical cohort. Br J Cancer (2004) 91(10):178794. doi: $10.1038 /$ sj.bjc.6602207

96. Foster C, Evans DG, Eeles R, Eccles D, Ashley S, Brooks L, et al. Predictive testing for BRCA1/2: attributes, risk perception and management in a multicentre clinical cohort. Br J Cancer (2002) 86(8):1209-16. doi: 10.1038/ sj.bjc. 6600253

97. Belisle-Pipon JC, Vayena E, Green RC, Cohen IG. Genetic testing, insurance discrimination and medical research: what the United States can learn from peer countries. Nat Med (2019) 25(8):1198-204. doi: 10.1038/s41591-0190534-z

98. Huizenga CR, Lowstuter K, Banks KC, Lagos VI, Vandergon VO, Weitzel JN. Evolving perspectives on genetic discrimination in health insurance 
among health care providers. Fam Cancer (2010) 9(2):253-60. doi: 10.1007/ s10689-009-9308-y

99. Allain DC, Friedman S, Senter L. Consumer awareness and attitudes about insurance discrimination post enactment of the Genetic Information Nondiscrimination Act. Fam Cancer (2012) 11(4):637-44. doi: 10.1007/ s10689-012-9564-0

100. Parkman AA, Foland J, Anderson B, Duquette D, Sobotka H, Lynn M, et al. Public awareness of genetic nondiscrimination laws in four states and perceived importance of life insurance protections. J Genet Couns (2015) 24(3):512-21. doi: 10.1007/s10897-014-9771-y

101. Tsimberidou AM, Fountzilas E, Nikanjam M, Kurzrock R. Review of precision cancer medicine: Evolution of the treatment paradigm. Cancer Treat Rev (2020) 86:102019. doi: 10.1016/j.ctrv.2020.102019

102. Lambert SA, Abraham G, Inouye M. Towards clinical utility of polygenic risk scores. Hum Mol Genet (2019) 28(R2):R133-r142. doi: 10.1093/hmg/ddz187

103. Saulsberry K, Terry SF. The need to build trust: a perspective on disparities in genetic testing. Genet Testing Mol Biomarkers (2013) 17(9):647-8. doi: $10.1089 /$ gtmb.2013.1548
104. Smith CE, Fullerton SM, Dookeran KA, Hampel H, Tin A, Maruthur NM, et al. Using Genetic Technologies To Reduce, Rather Than Widen, Health Disparities. Health affairs (Project Hope) (2016) 35(8):1367-73. doi: 10.1377/ hlthaff.2015.1476

105. Helmy M, Awad M, Mosa KA. Limited resources of genome sequencing in developing countries: Challenges and solutions. Appl Transl Genom (2016) 9:15-9. doi: 10.1016/j.atg.2016.03.003

Conflict of Interest: The authors declare that the research was conducted in the absence of any commercial or financial relationships that could be construed as a potential conflict of interest.

Copyright (c) 2021 McInerney-Leo and Duncan. This is an open-access article distributed under the terms of the Creative Commons Attribution License (CC BY). The use, distribution or reproduction in other forums is permitted, provided the original author(s) and the copyright owner(s) are credited and that the original publication in this journal is cited, in accordance with accepted academic practice. No use, distribution or reproduction is permitted which does not comply with these terms. 